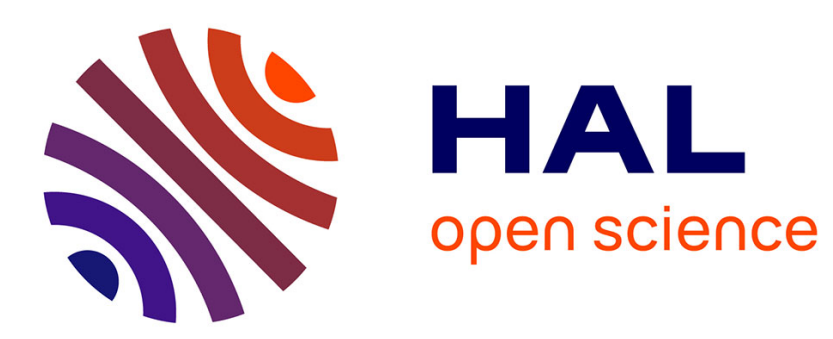

\title{
Un poeta olvidado de finales del siglo XVII: Josef Pérez de Montoro
}

\author{
Alain Begue, Josef Pérez de Montoro
}

\section{To cite this version:}

Alain Begue, Josef Pérez de Montoro. Un poeta olvidado de finales del siglo XVII: Josef Pérez de Montoro. Actas del V Congreso de la Asociación Internacional Siglo de Oro. Münster 1999, 2001. hal-02522966

\section{HAL Id: hal-02522966 https://hal.science/hal-02522966}

Submitted on 14 Apr 2020

HAL is a multi-disciplinary open access archive for the deposit and dissemination of scientific research documents, whether they are published or not. The documents may come from teaching and research institutions in France or abroad, or from public or private research centers.
L'archive ouverte pluridisciplinaire $\mathbf{H A L}$, est destinée au dépôt et à la diffusion de documents scientifiques de niveau recherche, publiés ou non, émanant des établissements d'enseignement et de recherche français ou étrangers, des laboratoires publics ou privés. 


\section{Un poeta olvidado de finales del siglo XVII : Josef Pérez de Montoro}

\section{Alain BÈGUE \\ Universidad de Toulouse-le Mirail}

Este trabajo consistirá en presentar los primeros resultados de una investigación sobre un fecundo poeta olvidado de fines del siglo XVII : Josef Pérez de Montoro.

Hasta ahora, el poeta y dramaturgo valenciano Josef Pérez de Montoro, cuyo período de gran actividad creadora se sitúa durante el reinado de Carlos II, sólo ha sido objeto de estudios parciales que se sirvieron de su obra como ejemplo para unos análisis lingüísticos de la poesía del XVII. Así, dos artículos recientes se dedican al estudio del dialecto asturiano y a la pronunciación del portugués en unos villancicos gaditanos. Otro artículo que toma como punto de partida la edición de un soneto en portugués ${ }^{1}$, hace una breve presentación de nuestro autor tanto biográfica como literariamente.

Además, la única edición moderna de composiciones poéticas suyas fue la de Luis Rosales que, deseoso de presentar un amplio y nuevo elenco de escritores de finales del XVII en su antología de la poesía española del Siglo de Oro $^{2}$, incluyó dos sonetos de Pérez de Montoro que ya habían sido editados en sus obras póstumas.

No faltan sin embargo los testimonios que indican el interés y el aprecio que despertaba en su época.

Así en 1682, en vida pues, de nuestro poeta, el editor de los poemas de Sor Juana Inés de la Cruz incluye una respuesta en verso del Fénix mexicano al romance de Montoro « Amor sin celos, question ... », respuesta que presenta a Pérez de Montoro como « uno de los más célebres poetas de este siglo $»^{3}$.

Posteriormente, el librero madrileño Juan de Moya, al reunir y dar a la estampa sus obras póstumas ${ }^{4}$ estipula al tratar de Montoro :

Como el nombre de Don Joseph Pérez de Montoro ocupa toda la esfera de la fama, no necesita otra recomendacion esta obra, que ser suya... 5

En el mismo sentido se pronuncia otro crítico del siglo XVIII, el valenciano Vicente Ximeno, al afirmar que :

\section{(...) celebran altamente sus Obras los mejores Poetas. ${ }^{6}$}

\footnotetext{
${ }^{1}$ Camus Bergareche, B., «La pronunciación del portugués del siglo XVII en unos villancicos gaditanos », Anuario Galego de Filoloxia, 1992, 19, 397-407 ; "El dialecto asturiano en el siglo XVII », Boletín del Real Instituto de Estudios Asturianos, 1992, 46:140, 375-92 ; Serralta, F., " Un sonnet "portugais" de José Pérez de Montoro », en Arquivos do Central Cultural Portugués, 1983, 19, 575-80.

${ }^{2}$ Rosales, L., Poesia española del Siglo de Oro, Madrid, Salvat, 1970. Biblioteca básica Salvat ; 87 . 189-90

${ }^{3}$ de Asbaje y Rodríguez de Cantillana, J. I., Poemas, Zaragoza, 1682.

${ }^{4}$ Pérez de Montoro, J., Obras posthumas lyricas..., recogidas y dadas a la estampa por Juan de Moya, Madrid, Antonio Marín, 1736. Dos tomos, el tomo primero (Obras humanas) : 12 fol. s.n. +468 p. +9 fol. de índice ; el tomo segundo (Obras sagradas) $: 2$ fol. s.n. +458 p. +9 fol. de índice.

${ }_{6}^{5}$ Pérez de Montoro, J., op. cit., t. I, Prólogo al lector, 1.

${ }^{6}$ Ximeno, V., Escritores del Reyno de Valencia..., Valencia, Joseph Estevan Dolz, 1747-1749, 2 tomos. Ver el tomo II, 116.
} 
Por supuesto, todas estas apreciaciones laudatorias pueden atribuirse a motivos circunstanciales, tales como promover a un escritor para fines meramente comerciales, como en el caso de Juan de Moya, o poner de realce a un compatriota, en el caso de Vicente Ximeno. Ahora bien, existen asimismo criterios objetivos que permiten confirmar la notoriedad literaria de Pérez de Montoro y la audiencia de sus contemporáneos, aunque sólo sea el hecho de que su obra poética está incluida en numerosas recopilaciones y otras florestas manuscritas de finales del XVII - un poco más de treinta hasta la fecha- conservadas hoy en distintas bibliotecas tanto españolas como extranjeras.

Entonces, me ha parecido importante averiguar el porqué de la fama que tuvo en vida, claro que en un periodo carente de grandes escritores, un autor tan olvidado en nuestro siglo.

\section{Elementos para una biografía}

Los datos de tipo biográfico conocidos son todavía muy escasos, aunque espero completarlas en breve, siguiendo algunas interesantes pistas de investigación.

Nuestro poeta era natural del Reino de Valencia pues nació en la ciudad de Játiva en el año de 1627.

Acerca de sus antepasados, el editor de sus Obras póstumas indica que habían bajado de las "Montañas de Burgos » para establecerse en los parajes más amenos de la costa mediterránea. Se debe tomar con cautela este último dato puesto que la región conocida como la Montaña era el solar obligado de cuantos pretendían recalcar su limpieza de sangre y, de esta manera, medrar en la sociedad.

Sobre su juventud, los únicos elementos biográficos conocidos se limitan a unos estudios de música que cursó « en sus primeros años ${ }^{7} »$. El propio Pérez de Montoro, en una carta dirigida a un amigo de Játiva en los años ochenta, dice acerca de su formación :

UMd sabe la poca aplicacion que en mis tiernos años tuue a los estudios pues en ninguna facultad perficione siquiera los prinzipios (...) porque en mi no ay mas siensia que una Bachilleria adquirida por el oido y guardada en la memoria desde donde suele uenirse tal vez para la pluma.

Sus estudios de música no fueron aprovechados, sino acaso en la musicalidad de sus versos, ya que se le señala años más tarde como vistamayor y alcaide de la Real Aduana de Sevilla y, después, de Cádiz, hasta su fallecimiento ${ }^{8}$.

Es de señalar que los períodos de estancia de Pérez de Montoro en estas dos ciudades resultan difíciles de averiguar pues las fechas avanzadas en ciertas ocasiones se invalidan entre sí. Esto ocurre por ejemplo con la edición del Apólogo membral escrito por don Francisco Godoy y editado en 1682, que presenta a nuestro autor como « vista, y Alcaide de la real Aduana de Sevilla, amigo del Autor " mientras otro señala su participación en una academia que se celebró en Cádiz el 22 de diciembre de 1672 para festejar el cumpleaños de la reina madre Mariana de Austria.

Otras fuentes señalan también la estancia en Madrid de don José Pérez de Montoro y de su familia durante la terrible peste de 1684-1685, y sin duda alguna debió de viajar a la corte en varias ocasiones.

\footnotetext{
${ }^{7}$ Ibid., « No avia estudiado sino un poco de Musica en sus primeros años ... », 116 a.

${ }^{8}$ Ibid., « Fue Secretario de su Magestad, y Vistamayor de las Reales Aduanas del Puerto, y Ciudad de Cadiz. »
} 
Su deseo de ascenso social le llevó a entrar al servicio de distintos miembros de la alta nobleza castellana -a semejanza de numerosos contemporáneos suyos- como fueron por ejemplo los marqueses de Jamaica, también duques de Veragua, descendientes del almirante Colón, o los duques de Medinaceli, lo cual se refleja en la abundancia de poemas panegíricos y en la utilización de la poesía como género epistolar.

Este deseo de ascenso social aparece asimismo en el título de secretario del Rey que lucía, seguramente de forma honorífica ya que su nombre no aparece en los libros de quitaciones de Corte del Archivo General de Simancas.

Pese a ello, José Pérez de Montoro falleció en Cádiz el 21 de diciembre de 1694 «sin más gages que el título y honores de Secretario del Rey ${ }^{9} »$ y fue enterrado en el convento de San Agustín de esta misma ciudad, teniendo su lápida como epígrafe : NON PLUS ULTRA ${ }^{10}$.

$\mathrm{Su}$ largo exilio, debido a razones profesionales, se tradujo por la añoranza de la tierra patria que experimentaba y su deseo de volver a sus tierras natales, lo que plasmó en una carta con estas palabras : « Dios sabe quanto quisiera entregar la vida donde la recibí. »

Acerca de la fecha de su defunción, queda un importante problema pues Julián Paz, en su Catálogo $^{11}$, fecha la redacción de una loa de Pérez de Montoro en 1701. Del mismo modo, los títulos de ciertos villancicos editados en sus obras póstumas por Juan de Moya indican que fueron cantados en 1695, contradiciendo así la fecha de defunción avanzada por el mismo editor. Aunque en este último caso las letras de textos escritos antes de 1694 hubieran podido ser utilizadas de forma póstuma, queda claro que su fecha de defunción sigue entonces sin fijación definitiva, aunque espero encontrar en breve al respecto documentos fidedignos.

\section{Su actividad literaria}

En el plano literario, nuestro poeta y dramaturgo valenciano se ubicaba en el corazón de las distintas manifestaciones de la vida cultural de las dos ciudades más importantes de Andalucía : Sevilla y Cádiz. Del mismo modo, debió de frecuentar en algunas ocasiones los ambientes literarios de la corte madrileña. Una lectura rápida de su obra lo confirma y refleja su participación activa en las academias, justas y otros certámenes, que tanto gustaron y florecieron en la segunda mitad del siglo XVII.

$\mathrm{Su}$ activa labor poética la refleja también los poemas, críticos y a veces polémicos, contra otros escritores de su tiempo. Así, Fermín de Sarasa y Arce, gentilhombre del duque de Medinaceli, quizás rival de nuestro autor por su posición profesional, fue el blanco predilecto de sus críticas mordaces como lo prueban nada menos que diez romances, un soneto y un ovillejo, composiciones poéticas escritas todas para contradecir poemas de Sarasa. También son valiosas las respuestas en verso del autor criticado ya que nos encontramos ante una verdadera correspondencia en verso sobre temas y concepciones divergentes.

Lo mismo ocurrió con otros escritores de la época, tanto menores tales como Diego de Contreras -criado del duque de Veragua-, Francisco de Villamayor, como de mayor fama, con en el caso de Francisco de Avellaneda o Francisco Bances Candamo. De la misma manera, han llegado hasta nosotros varios poemas del mismo género escritos por Pérez de Montoro pero desgradaciamente sin las obras correspondientes.

El caso inverso también se presentó, y la religiosa mexicana Sor Juana Inés de la Cruz lo demostró contradiciendo una definición que de los celos de amor hizo nuestro poeta valenciano. Este tipo de poesía basada en las oposiones temáticas y/o formales tiene toda su

\footnotetext{
${ }^{9}$ Pérez de Montoro, J., op. cit., t. I, Prólogo al lector, 2.

${ }^{10}$ Ibid.

${ }^{11}$ Paz Espeso, J., Catálogo de las piezas de teatro que se conservan en el Departamento de Manuscritos de la Biblioteca Nacional, Madrid, Patronato de la Biblioteca Nacional, 1934-1989. Tomo I, 523, nº 3463.
} 
importancia en la medida que permite aproximarse a varias corrientes poéticas, a varias concepciones de la poesía de un período aún mal conocido y oscuro.

Todo lo que he venido diciendo hasta ahora confirma la importancia de un estudio biográfico, estudio que permitirá conocer mejor el funcionamiento de los mundillos literarios sevillano, gaditano y madrileño de la segunda mitad del siglo XVII.

\section{Su obra}

En cuanto a su obra, a la hora de localizarla, se planteó, como para muchos escritores de su época, el problema de su verdadera autoría. Las obras sueltas o insertadas en florestas suelen ser atribuidas a Joseph Pérez de Montoro, o a veces solamente Montoro, lo que mueve a confusiones homonímicas con el famoso poeta del siglo XV, Antón de Montoro, o con el religioso Fray José Montoro, que, a ejemplo de nuestro autor, desarrolló su actividad literaria a finales del XVII. De la misma manera, algunos poemas suyos aparecen con el nombre de Montero, provocando así la confusión con otro contemporáneo suyo, Román Montero de Espinosa.

Tras despejar al repecto no pocas incertidumbres nos encontramos ante una obra de gran riqueza. En efecto, si los temas, el estilo o las formas poéticas escogidas por Pérez de Montoro, en cuanto heredero de una larga y polimórfica tradición poética, no difieren de los usados en la época, precisamente por ello es su obra, aparte de su interés específico, un muestrario muy completo de los temas y de los metros que estaban de moda en su época.

Las numerosas composiciones poéticas -en número de 393- editadas en sus obras póstumas de 1736 y repartidas en dos volúmenes revelan la gran diversidad de su inspiración y el intento de plasmar su energía creadora en cuantos géneros y metros tenía a su alcance ${ }^{12}$.

A las obras de estos dos tomos póstumos cabría añadir las numerosas ediciones sueltas de nuestro autor así como las obras que he podido encontrar, y que seguramente quedan por encontrar en las distintas recopilaciones manuscritas del siglo XVII -entre las cuales muchas inéditas-, lo que no hace sino confirmar la importancia de Pérez de Montoro en el panorama literario de las postrimerías del barroco.

En cuanto a las líneas temáticas de su obra no he destacado de momento ninguna especificidad particular ya que abarca casi todo el elenco temático de la época, excluyendo la poesía mitológica. Así pues, nos encontramos frente a poemas amorosos, morales, religiosos, descriptivos, panegíricos y laudatorios, heroicos, funerales y elegíacos, satíricos y burlescos.

Estas últimas obras se han quedado generalmente sin editar pues se tiñen muchas veces de una tonalidad erótico-burlesca. Tenemos por ejemplo títulos evocadores como « A una commadre de parir que se casó con un enterrador », «A una Dama que se descasò solo

\footnotetext{
${ }^{12}$ En efecto, las Obras posthumas lyricas humanas constan de 181 poemas, la gran mayoría de los cuales son romances (74). Pero entran también en su composición sonetos (57), redondillas (27), décimas (5), quintillas (3), octavas (2), letras, una seguidilla, una jácara, una endecha real y un ovillejo. También están insertados ocho jeroglíficos que se hicieron para el túmulo de la reina doña María Luisa en Cádiz, siete dísticos que representan los siete vicios capitales que escribió para una tarasca de Cádiz, así como cuatro obras teatrales : dos loas palaciegas, un entremés y un baile. De momento, entre estas últimas, sólo queda comprobada la autoría de las loas. En cuanto a las Obras posthumas lyricas sagradas, 212 composiciones poéticas las forman, de las cuales 169 son villancicos de estructura muy diversa. Están reunidas también epístolas (13), jácaras (8), romances (7), sonetos (6), quintillas (2), redondillas (2), una canción, unas sextillas así como una letanía.
} 
por casarse con un Capón » o también «A un Sacristán, y a un Doctor grandes amigos », títulos que reflejan la pervivencia de motivos antiguos.

He hablado también de muestrario pues su poesía revela influencias de los grandes poetas de su tiempo. Así, su poesía demuestra que fue lector ferviente de Luis de Góngora, a quien dedicó especial atención, como lo revela un soneto de elegía funeral editado en sus obras póstumas :

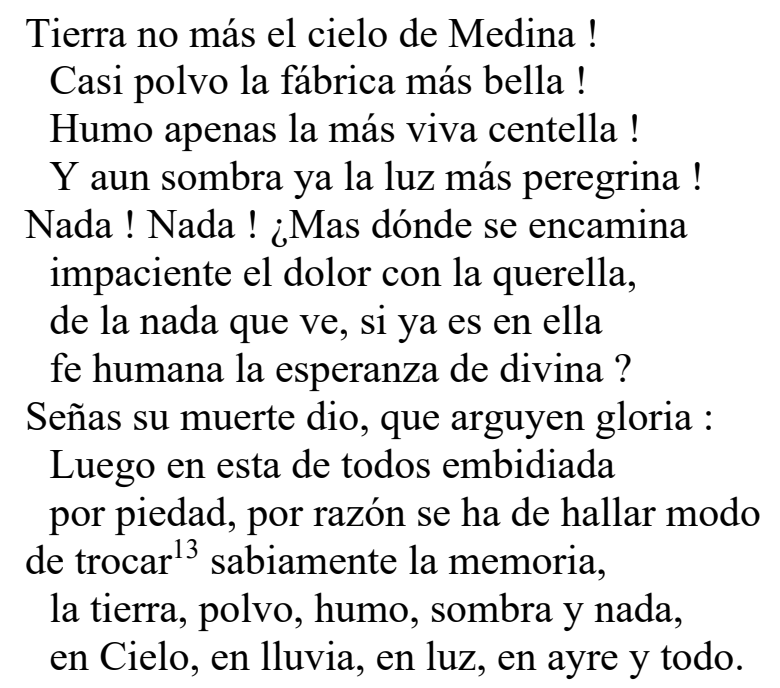

Asimismo son muy evocadoras unas octavas tituladas "Ponderose en una ocasión aver encajado Góngora en un verso las voces de Cuerno, Alcón, Cascabel, Cavallo, y Perro : y Montoro lo duplicó en estas OCTAVAS. »

Otros procedimientos recurrentes en su poesía traducen una asimilación de la rica poesía que heredó pero, no pudiendo todavía presentar análisis definitivos ni desarrollar el tema, me limitaré con recoger los testimonios de algunos críticos de principios del siglo XVIII.

Según Vicente Ximeno, al que ya he aludido, la poesía de Montoro era apreciada por :

la fecundidad de sus conceptos, facilidad de reducirlos al numero, y por la dulzura, propiedad, energia, y elegancia de sus hermosas expressiones. ${ }^{14}$

De la misma manera lo elogian los encargados de aprobar la edición de sus obras póstumas.

Así el R.P. Carlos de la Reguera, de la compañía de Jesús destaca :

lo fluido, y sonoro del metro : lo alegre, y vivo de las expressiones : la agudeza en el decir, y las promptitudes en los conceptos, con lo que bebe toda el alma, y la viveza à nuestro idioma $(\ldots)^{15}$

\footnotetext{
${ }^{13}$ El poema editado en las Obras posthumas humanas dice "toca" y lo rectifico por "troca"

${ }^{14}$ Ximeno, V., op. cit., 116 a y b.

${ }^{15}$ Pérez de Montoro, J., Op. cit., APROBACION DEL R.P. CARLOS DE LA / Reguera, de la Compañia de Jesus, Maestro de / Mathematicas en el Colegio Imperial de esta Corte.
} 
En el mismo sentido aboga otro jesuita, don Marcos Domínguez de Alcántara, al realzar :

la amenidad de sus assumptos, y pureza de estilo $(. . .)^{16}$

Además, la obra del poeta valenciano Josef Pérez de Montoro pone en evidencia una serie de procedimientos propios y significativos que no puedo detallar ahora, procedimientos que ya dejan presagiar la poesía del Setecientos.

No he pretendido hacer aquí sino presentar a un poeta que es un espejo de la poesía que se practicaba a fines del siglo XVII en los mundillos literarios de Sevilla, Cádiz y Madrid. Espero presentar, para una temprana fecha, un estudio más profundizado de su vida y de su obra que permita darle, por modesto que sea, un lugar en el panorama literario del periodo barroco.

${ }^{16}$ Ibid., APROBACION DE DON MARCOS / Dominguez de Alcantara, Pres- / bytero, \&c. 